18

\title{
Effects of gradients of the electron density on Earth-space communications
}

\author{
SANDRO M. RADICELLA $\left({ }^{1}\right)$, BRUNO NAVA $\left({ }^{1}\right)$, PIERDAVIDE COÏSSON $\left({ }^{1}\right)$, \\ LEONARD KERSLEY $\left({ }^{2}\right)$ and GRAHAM J. BAILEY $\left({ }^{3}\right)$ \\ (1) The Abdus Salam International Centre for Theoretical Physics (ICTP7, \\ Aeronomy and Radiopropagation Laboratory, Trieste, Italy \\ $\left.{ }^{2}\right)$ University of Wales, Aberystwyth, U.K. \\ (') University of Sheffield, U.K.
}

This paper is a review of the main results achieved in the framework of COST 271 Action Working Group 4, under the activities of the Work Package 4.4. The first topic treated deals with the influence of ionospheric space and time gradients in the slant to vertical and vertical to slant ionospheric delay conversion when the thin shell approximation of the ionosphere is assumed and with the effects of geomagnetic activity on the errors that this conversion introduces. The second topic is related to the comparison of ionospheric topside models with experimental electron density profiles to check the ability of the models to reproduce the observed topside shape and characteristics that determine the electron density gradients. The analysis that has been done allows pointing out the changes needed to improve the models. Finally a third topic covers a model simulation study of the total electron content that can be encountered in GPS-to-geostationary satellite ray paths. It takes into account that the propagation paths for such satellite-to-satellite links are very long and they have the potential to intersect regions of the ionised atmosphere where the electron density is high when the geometry is close to eclipse.

\subsection{INTRODUCTION}

1) Ionosphere introduces a group delay in satellite signal and is at present time the main source of error for satellite navigation systems that operate at single frequency. The presence of obliquity factor errors introduced in the estimation of vertical ionospheric delays from slant measurements due to the thin shell approximation has been reported in the open literature only in a qualitative way. In particular the possible dependence of these errors on different parameters has not been described with a systematic approach. NeQuick model is used to assess this dependence and a reduced number of tests with experimental data are also performed (Nava, 2000).

Some ionospheric features observed during geomagnetic disturbed periods, were investigated using particular sets of GPS derived slant total electron content measurements: «Supertruth» data. These data are high quality slant total electron content measurements obtained at $5 \mathrm{~s}$ sampling rate, using 25 ground stations located in U.S.A., during specific time periods. For the present work the data related to the storm periods April 05-08 and July 15-16 2000 were used (Nava and Radicella, 2003a).

2) Information about the topside electron concentration distribution is not obtainable from ground-based measurements. In the past decades only few satellites were equipped with ionosondes to sound the ionosphere above the F2 maximum (topside sounders). Moreover, only a few percent of 
data recorded in the 60s and 70s were processed at that time due to the limited techniques available for automatic ionogram scaling. Only in the last couple of years quite large amounts of newly scaled ionograms have been made available online (Bilitza et al., 2003). Ionospheric electron density models have their topside formulation based on old databases or different kind of measurements. Thus it is very important to test them using all datasets that provide new information. Vertical profiles are of particular importance since they provide information on the gradients of electron concentration and they contain also information about $f o F 2$, which is generally used by models as anchor point to describe vertical profiles. NeQuick and IRI models, have been used in this work for comparisons with topside sounders profiles (Coïsson, 2002).

3) While extensive studies have been carried out over several decades on the effects of the ionised atmosphere on satellite-to-ground propagation paths very little work has been done on ray paths involving links between satellites. However, with the increasing use of radio systems for practical applications, particularly satellite-based navigation and positioning, interest is now turning to propagation effects on satellite-to-satellite paths. One specific aspect driving such investigations is concern over future requirements for the station-keeping of satellites in the commercially very important, but potentially congested, geostationary orbit. Geostationary satellites are tracked currently using a network of ground stations. A future possible development could involve positioning making use of a satellite navigation system, like GPS. However, since the GPS system was designed primarily for terrestrial users the satellites have nadir-directed antennas. In consequence, reception in geostationary orbit would involve use of signals transmitted by GPS satellites on the far side of the Earth. The propagation paths for such satellite-to-satellite links are very long and they have the potential to intersect regions of the ionized atmosphere where the electron density is high when the geometry is close to eclipse. It is thus of considerable interest to investigate propagation effects on such links. Since the main factors that cause degradation to practical systems, resulting in positioning errors, are dependent directly on the path integral of the electron density, it is important that assessment is made of the possible magnitudes of the Total Electron Content (TEC) likely to be encountered in GPS-to-geostationary satellite propagation. Such an assessment is done using an adequate model.

\subsection{OBLIQUITY FACTOR ERROR IN SLANT TO VERTICAL AND VERTICAL TO SLANT IONOSPHERIC DELAY CONVERSION INCLUDING GEOMAGNETIC EFFECTS}

\subsubsection{Conversion error evaluation}

The error introduced by the obliquity factor is defined through the following equations:

$$
\begin{aligned}
& \text { sTEC }=\int_{\text {Receiver }}^{\text {Satellite }} N_{e}(s) d s \\
& \mathrm{vTEC}_{P P}=\int_{0 \mathrm{~km}}^{20000 \mathrm{~km}} N_{e}\left(\phi_{P P}, \lambda_{P P}, h\right) d h \\
& \text { Converted vTEC } \mathrm{vT}_{P P}=\mathrm{sTEC} \cdot \cos (\chi) \\
& \text { Error }=\text { Converted vTEC }{ }_{P P}-\mathrm{vTEC}_{P P}
\end{aligned}
$$

where $\phi_{P P}$ is the latitude of the pierce point, $\lambda_{P P}$ is the longitude of the pierce point and $\chi$ is the satellite zenith angle at the pierce point. 


\subsubsection{Model simulations}

The first analysis has been done using NeQuick model (see description in Section 18.3 of this paper) to simulate «average» ionosphere electron density $N_{e}$ without storm or TID conditions. Pierce points height has been assumed at $350 \mathrm{~km}$ and only spherical reference frames were used.

\subsubsection{Analysis and Results (Nava, 2000)}

Errors were calculated for each ray-path determined by 31 observing stations and the positions assumed by 24 GPS satellites, every $10 \mathrm{~min}$, along their orbits during $24 \mathrm{~h}$. The calculations were done for a representative day in January, April, July for moderate solar activity (Solar Flux = 130 f.u.) and for a representative day in January, April, July for high solar activity (Solar Flux = 200 f.u.).

To better understand error behavior with respect to satellite elevation angle, satellite azimuth and ground station latitude, two approaches were considered: ground station approach and pierce point approach. In the first approach NeQuick was used to simulate sTEC from a ground receiver and a second point having $20000 \mathrm{~km}$ height, elevation from $0^{\circ}$ to $85^{\circ}$, step $5^{\circ}$ (measured with respect to ground station) and azimuth from $0^{\circ}$ to $355^{\circ}$, step $5^{\circ}$ (measured with respect to ground station). Figure 18.1 shows an example of error dependence on satellite elevation and azimuth, with respect to ground station latitude, for latitudes $25^{\circ} \mathrm{N}, 35^{\circ} \mathrm{N}, 45^{\circ} \mathrm{N}$ and $55^{\circ} \mathrm{N}$ respectively, for $15^{\circ} \mathrm{E}$ and 20:00 UT.

For the pierce point approach, calculations were done using pierce points with different latitudes and longitudes. NeQuick was used to simulate sTEC for all the paths passing «through» the same pierce point. In these cases either the generic receiver or the generic second integration point had suitable elevation and azimuth, measured with respect to the pierce point. In particular the second integration point had $20000 \mathrm{~km}$ height, elevation from $20^{\circ}$ to $85^{\circ}$, step $5^{\circ}$ (measured with respect to
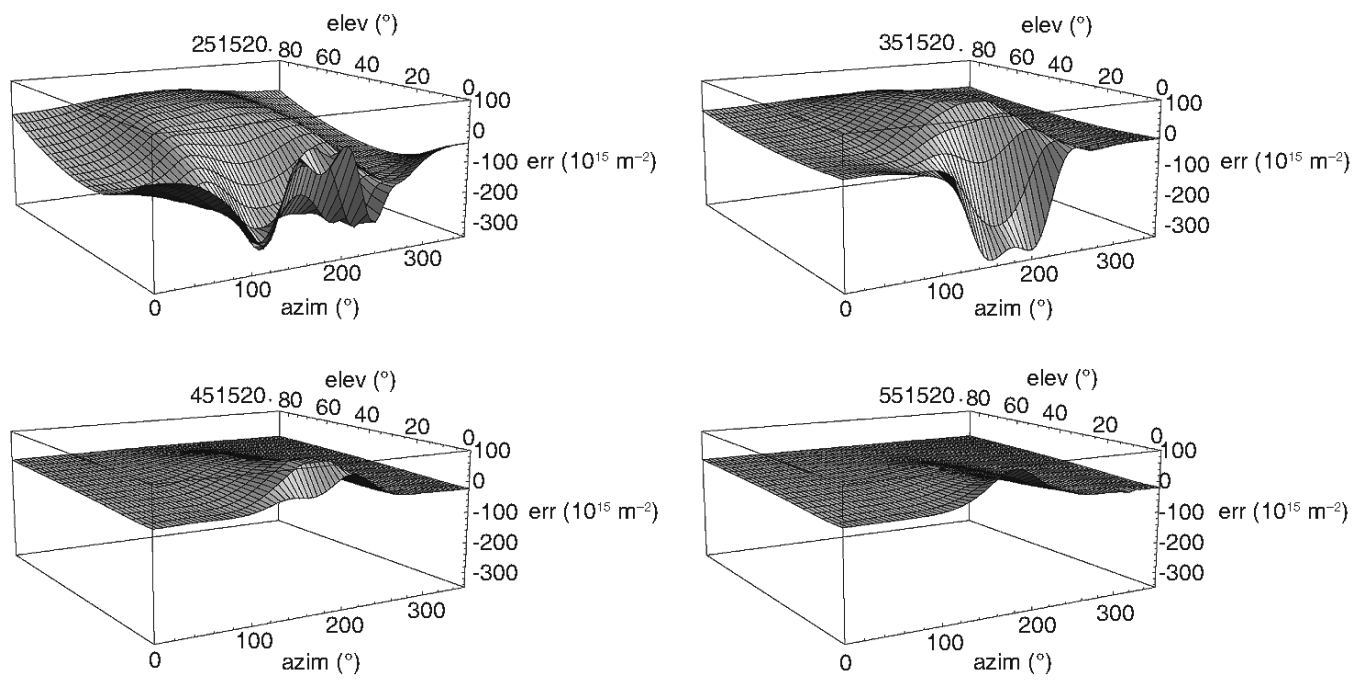

Fig. 18.1. Ground station approach: error dependence on satellite elevation and azimuth. Ground station latitude $25^{\circ} \mathrm{N}, 35^{\circ} \mathrm{N}, 45^{\circ} \mathrm{N}, 55^{\circ} \mathrm{N}$ respectively, for $15^{\circ} \mathrm{E}$ and $20: 00 \mathrm{UT}$. 

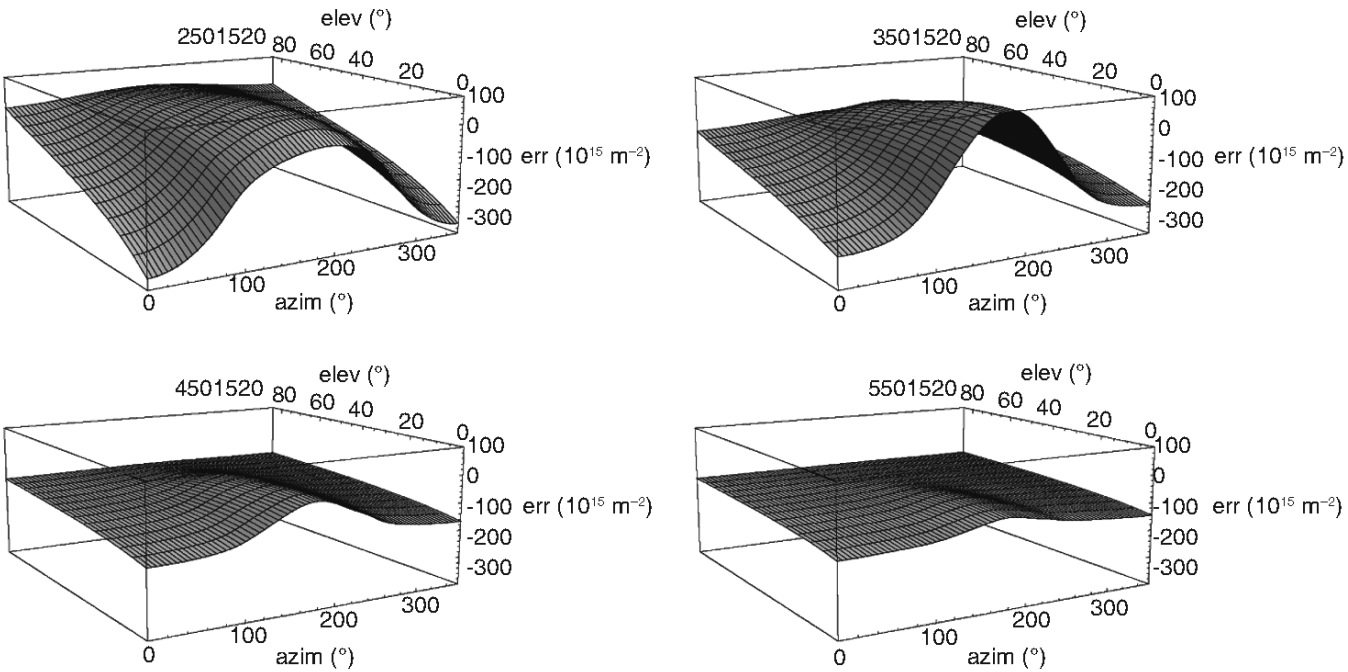

Fig. 18.2. Pierce point approach: error dependence on satellite elevation and azimuth measured with respect to pierce point. Pierce point latitude $25^{\circ} \mathrm{N}, 35^{\circ} \mathrm{N}, 45^{\circ} \mathrm{N}, 55^{\circ} \mathrm{N}$ respectively, for $15^{\circ} \mathrm{E}$ and $20: 00 \mathrm{UT}$.

pierce point) and azimuth from $0^{\circ}$ to $355^{\circ}$ step $5^{\circ}$ (measured with respect to pierce point). Figure 18.2 shows an example of error dependence on satellite elevation and azimuth, with respect to pierce point latitude, for latitudes $25^{\circ} \mathrm{N}, 35^{\circ} \mathrm{N}, 45^{\circ} \mathrm{N}$ and $55^{\circ} \mathrm{N}$ respectively, for $15^{\circ} \mathrm{E}$ and 20:00 UT.

The results obtained from the analysis done using the NeQuick model simulations indicate that the conversion factor error depends on: satellite elevation angle (increasing elevation leads to decreasing lerrorl), satellite azimuth (by sectors with a complicated structure), ground station latitude (increasing latitude leads to decreasing lerrorl), solar activity (increasing solar activity leads to increasing lerrorl) and season (following seasonal TEC trends).

\subsubsection{Results obtained from experimental data}

To check the results obtained with the model simulation an investigation about mapping function errors was performed using experimental data. The technique adopted is based on the analysis of all pairs of ground station to satellite links that, for a given epoch, define «coinciding» pierce points.

Two pierce points $p p 1$ and $p p 2$, belonging to the same pair of links and having latitude $\phi_{p p i}$ and longitude $\lambda_{p p i}(i=1,2)$, were considered «coinciding» if

$$
\left|\phi_{p p 2}-\phi_{p p 1}\right|<0.2^{\circ}
$$

and

$$
\left|\lambda_{p p 2} / \cos \left(\phi_{p p 1}\right)-\lambda_{p p 1} / \cos \left(\phi_{p p 1}\right)\right|<0.2^{\circ} .
$$

If vTEC1 and vTEC2 are the two equivalent vTEC corresponding to $p p 1$ and $p p 2$, by definition should be

$$
\text { vTEC1 = vTEC2. }
$$


Table 18.I. Number of cases for which conversion errors exceed $5 \mathrm{TECu}$.

\begin{tabular}{ccc}
\hline Day & $\begin{array}{c}\mid \text { ptec2 } 2 \text { ptec } 1 \mid \\
>5 \text { TECu }\end{array}$ & $\begin{array}{c}\mid \text { ptec2 }- \text { ptec } 1 \mid>5 \text { TECu } \\
\text { and elevation of one satellite }>85^{\circ}\end{array}$ \\
\hline 10 Jul 2000 & 280 & $11(\mid$ ptec2 - ptec $1 \mid$ aver. $=6.7$ TECu $)$ \\
11 Jul 2000 & 312 & 0 \\
12 Jul 2000 & 117 & 0 \\
24 Jul 2000 & 118 & 0 \\
25 Jul 2000 & 231 & $10(\mid$ ptec2 - ptec1 $\mid$ aver. $=6.5$ TECu $)$ \\
26 Jul 2000 & 145 & 0 \\
\hline
\end{tabular}

If $\mathrm{vTEC} 1 \neq \mathrm{vTEC} 2$ we can say that at least one of vTEC 1 or vTEC 2 is affected by a mapping function error whose magnitude, in absolute value, is at least $\triangle \mathrm{TEC} / 2$, where we have defined $\triangle \mathrm{TEC}=\mid \mathrm{vTEC} 2+$ - vTEC1|.

Slant TEC data derived from GPS satellites tracked by 14 ground stations in Europe, provided by L. Ciraolo of IFAC, Florence (Italy), were used. In general TEC were given every $30 \mathrm{~s}$ for all the time of interest. It is important to notice that, since the method to estimate errors is based on the concept of coinciding pierce points, it is difficult to make meaningful statistics due to the reduced number of such coinciding points. As an example of the results obtained the number of cases for which $\mid$ ptec $2+$ - ptec $1 \mid>5 \mathrm{TECu}\left(1 \mathrm{TECu}=10^{16} \mathrm{~m}^{-2}\right)$ and, among them, how many correspond to situations for which one satellite has an elevation mask of $85^{\circ}$, are indicated in table 18.I.

The results obtained with experimental data tend to confirm the trend found with systematic simulations done using NeQuick model.

\subsubsection{Use of conversion errors to analyze ionosphere behaviour during geomagnetic disturbed periods (Nava and Radicella, 2003b)}

Some ionospheric features observed during geomagnetic disturbed periods, were investigated using particular sets of GPS derived slant total electron content measurements: «Supertruth» data. These data, kindly provided by the US WAAS community, are high quality slant total electron content measurements obtained at $5 \mathrm{~s}$ sampling rate, using 25 ground stations located in U.S.A., during specific time periods. For the present work the data related to the storm periods April 05-08 and July 15-16 2000 were used.

In order to have an overview of the ionosphere behavior during the above mentioned storms, the thin shell approximation for the ionosphere was assumed and all the slant total electron contents (sTEC) were converted to equivalent vertical total electron contents (vTEC) at the pierce points using the expression

$$
\mathrm{vTEC}=\operatorname{sTEC}^{\circ} \times \cos (\chi)
$$

where the mapping function $\cos (\chi)$ is (Breed et al., 1997)

$$
\cos (\chi)=\sqrt{1-\left(\frac{R_{E} \cos (E)}{R_{E}+h_{p p}}\right)^{2}} .
$$

The results obtained using this approach are shown in fig. 18.3. The left side panels represent equivalent vTEC values for April 06 at 23:00 UT, 23:50 UT and 01:00 UT, 02:00 UT; the right side pan- 

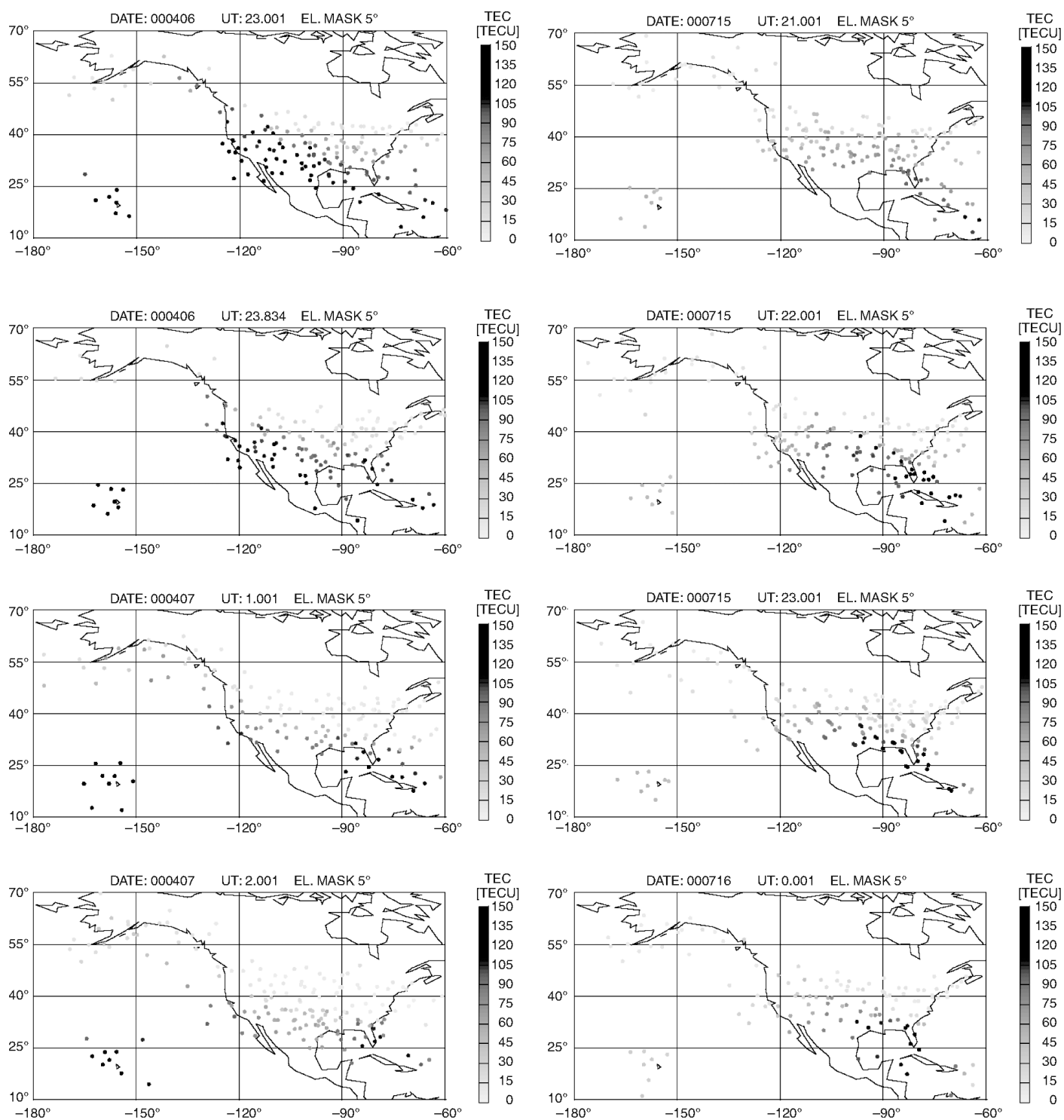

Fig. 18.3. Equivalent vTEC for April 06, 23:00, 23:50 UT; April 07, 01:00, 02:00 UT (left panels) and equivalent vTEC for July 15 21:00, 22:00, 23:00 UT; July 16, 00:00 UT (right panels).

els represent equivalent vTEC values for July 15 at 21:00, 22:00, 23:00 UT and 00:00 UT. In both cases a well defined regional storm effect is observable as an enhancement of the equivalent vTEC. In the case of the July 15 storm, the effect is more relevant, particularly for the south-east region of the U.S.A., because of the lower electron density background level. 
Nevertheless the highest (true) vTEC values were observed during July storm from Miami station: up to $213 \mathrm{TECu}$ with a satellite link at $80^{\circ}$ elevation.

In presence of strong ionospheric electron density gradients, the thin shell approximation for the ionosphere (Breed et al., 1997; Davies and Hartmann, 1997) used together with a simple mapping function to convert sTEC to vTEC, could lead to TEC conversion errors that depend on several parameters like for example satellite elevation, satellite azimuth, ground station location, local time, season and solar activity (Nava, 2000).

Being the positive phase of ionospheric storm a situation where strong electron density gradients can occur, an investigation about mapping function errors during geomagnetic disturbed periods was performed.

The technique adopted is based on the analysis of all pairs of ground station to satellite links that, for a given epoch, define «coinciding» pierce points as described above.

Using a shell height of $350 \mathrm{~km}$ and applying an elevation mask of $5^{\circ}$ to all ground to satellite links, all coinciding pierce points and the corresponding $\triangle$ TEC quantities (see above for $\triangle T E C$ definition) were computed for all epochs available during the days April 05-08 and July 15-16. Figure 18.4 illustrates $\triangle$ TEC quantities (corresponding to all U.S.A.) as a function of UT, for both ionospheric storms.

The Dst index values (obtained from http://swdcwww.kugi.kyotou.ac.jp/dstdir/index.html) for the corresponding periods were included in the figures to show the correlation between Dst index variation and mapping function errors magnitude.

It is important to notice how $\triangle \mathrm{TEC}$ values follow the «rising» of $-D s t$ index. This correspondence between $D s t$ index variation and increasing of $\triangle \mathrm{TEC}$ values during the geomagnetic events indicates that in some cases mapping function errors can be used to identify in near-real-time particular features of a disturbed ionosphere, like the presence of larger spatial electron density and TEC gradients. It is also important to underline that in some cases the minimum error on vTEC is almost $40 \mathrm{TECu}$.

To verify if the correlation between $D s t$ index and mapping function error was detectable at a smaller geographical scale, an analysis of $\triangle \mathrm{TEC}$ was performed on grids with an extension of $5^{\circ}$ in latitude and $5^{\circ}$ in longitude. In some regions this correlation was found as shown in fig. 18.5, while in other regions the correlation between $D s t$ index and $\Delta$ TEC values seemed to be absent. In these last cases, due to the low quantity of coinciding pierce points data, was not possible to establish if the correlation was not present or simply impossible to detect.

In order to identify possible ways to detect in near-real-time particular features of a disturbed ionosphere, an analysis of sTEC rate of change was performed for all possible single orbits determined by ground station to satellite links.
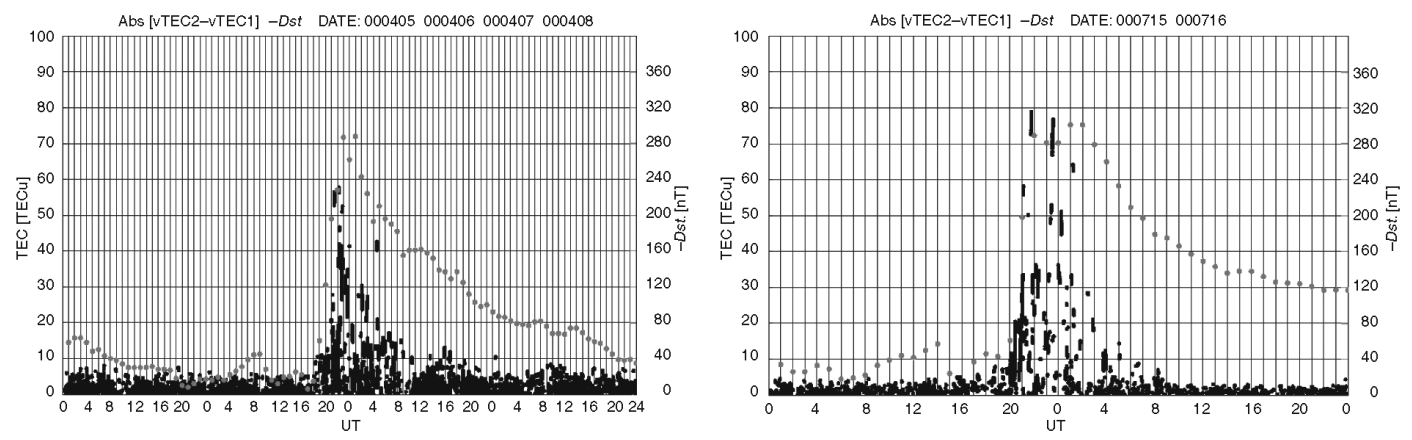

Fig. 18.4. $\triangle \mathrm{TEC}$ quantities and $-D s t$ index values as a function of UT for April 05-08 and for July 15-16. 

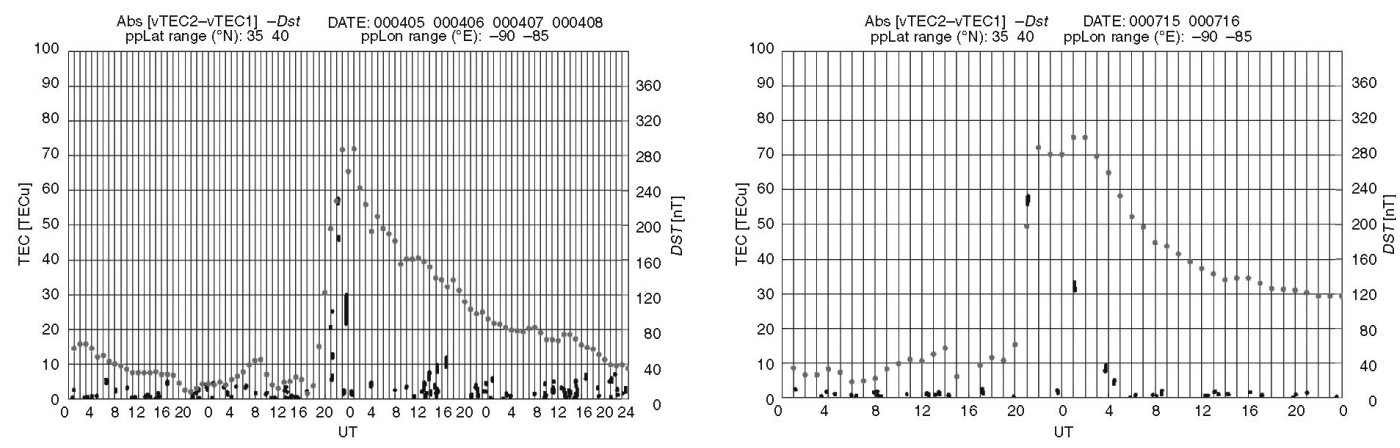

Fig. 18.5. $\triangle \mathrm{TEC}$ quantities and $-D s t$ index values as a function of UT for April 05-08 and for July 15-16. Here only pierce points lying in the $5^{\circ}$ by $5^{\circ}$ region $\left(35^{\circ} \mathrm{N}, 40^{\circ} \mathrm{N}\right)$ and $\left(-90^{\circ} \mathrm{E},-85^{\circ} \mathrm{E}\right)$ were considered.
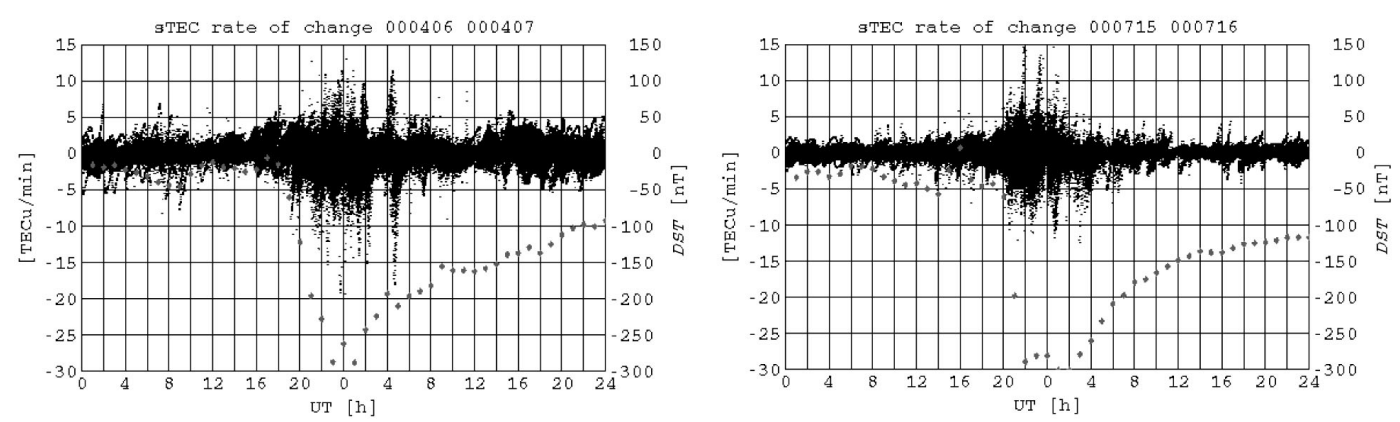

Fig. 18.6. STEC rate of change with $d t=1 \mathrm{~min}$ for April 06-07 and for July 15-16. Data extracted every $1 \mathrm{~min}$. Dst index values are also plotted.

Initially all sTEC rate of change were computed using a time interval of $1 \mathrm{~min}$. Data every minute were extracted and the results of this calculation are summarized in fig. 18.6, where sTEC rate of change computed along all possible «orbits» are plotted as a function of UT for the days April 06-07 and July 15-16. Dst index values for the corresponding periods are also plotted.

To better visualize sTEC behavior during a geomagnetic disturbed period, cumulative distributions of absolute values of sTEC rate of change were computed at the same UT for the two consecutive days that included the geomagnetic storm. In this way it was possible to compute sTEC rate of change when Dst index reached its minimum values and the corresponding UT for a period when the ionosphere could be considered relatively quiet. As a meaningful example, in fig. 18.7 are plotted the cumulative distributions of sTEC rate of change for the 00:00-01:00 UT of the day July 15 (left frame) and sTEC rate of change for the 00:00-01:00 UT of the day July 16.

It appears evident that during the disturbed period, the percentage of sTEC rate of change that exceeds a certain value is larger than during the corresponding hour of the previous (almost undisturbed) day.

A more specific study on single ground station to satellite links was performed in order to investigate possible relations between Dst index variation and sTEC behavior during geomagnetic disturbed period. In particular, for all ground station to satellite links, the moving averages (with a window length of $3 \mathrm{~min}$ ) of sTEC rate of change were computed. Some results are shown in fig. 18.8 as an example. 

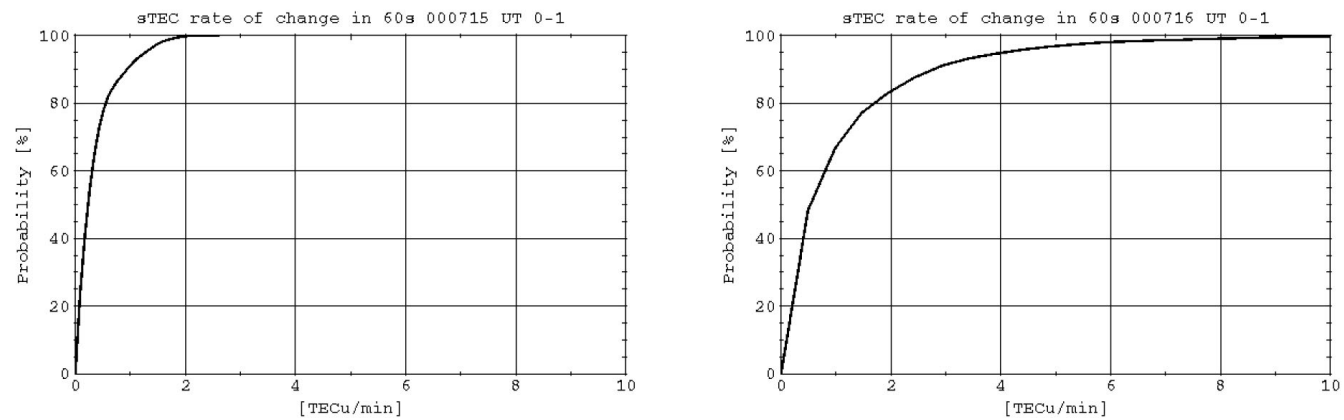

Fig. 18.7. Cumulative distributions of sTEC rate of change for July 15, 01:00 UT (left) and for July 16, 01:00 UT (right).
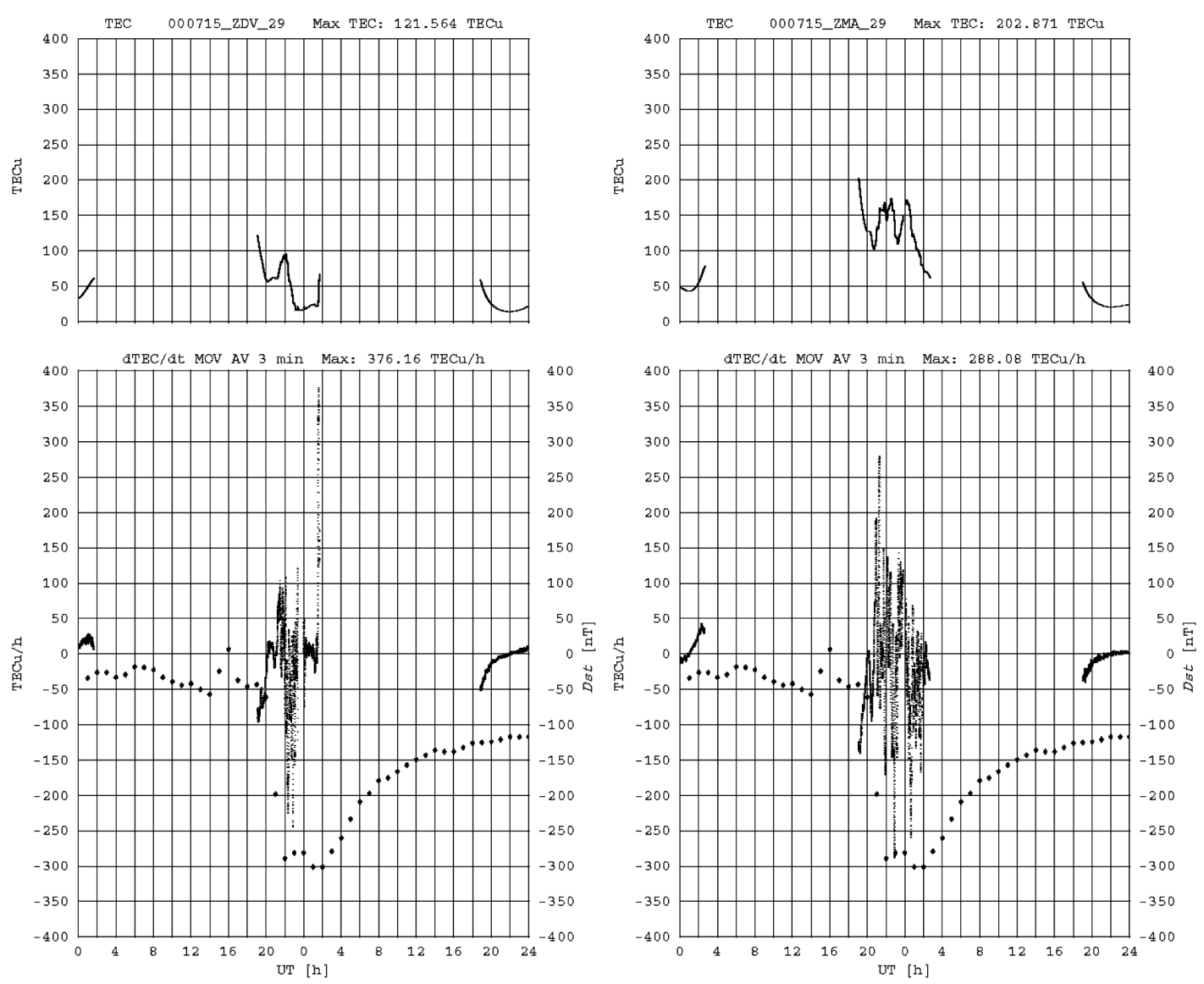

Fig. 18.8. sTEC, moving average (window length $=3 \mathrm{~min}$ ) of sTEC rate of change, satellite elevation and azimuth as a function of UT for July 15-16. Left panels refers to the link: Denver station $\left(40.2^{\circ} \mathrm{N}, 254.9^{\circ} \mathrm{E}\right)$, PRN 29. Right panels refers to the link: Miami station $\left(25.8^{\circ} \mathrm{N}, 279.7^{\circ} \mathrm{E}\right)$, PRN 29. Dst index values are also indicated (black points). 


\subsubsection{Ionosphere shell height (Nava and Radicella, 2003a)}

The problem of shell height determination for ionospheric studies is known (Leitinger et al., 1999). In the present case an empirical method to assess ionosphere shell height was applied, considering that the best shell height is the one that minimizes the mapping function errors.

In particular, the attention was focused on the possibility to reduce conversion errors related to a disturbed ionosphere. For this reason $\triangle \mathrm{TEC}$ were calculated for different ionospheric shell heights, ranging from $300 \mathrm{~km}$ up to $800 \mathrm{~km}$ with $50 \mathrm{~km}$ steps. An elevation mask of $20^{\circ}$ to all ground to satellite links was applied.
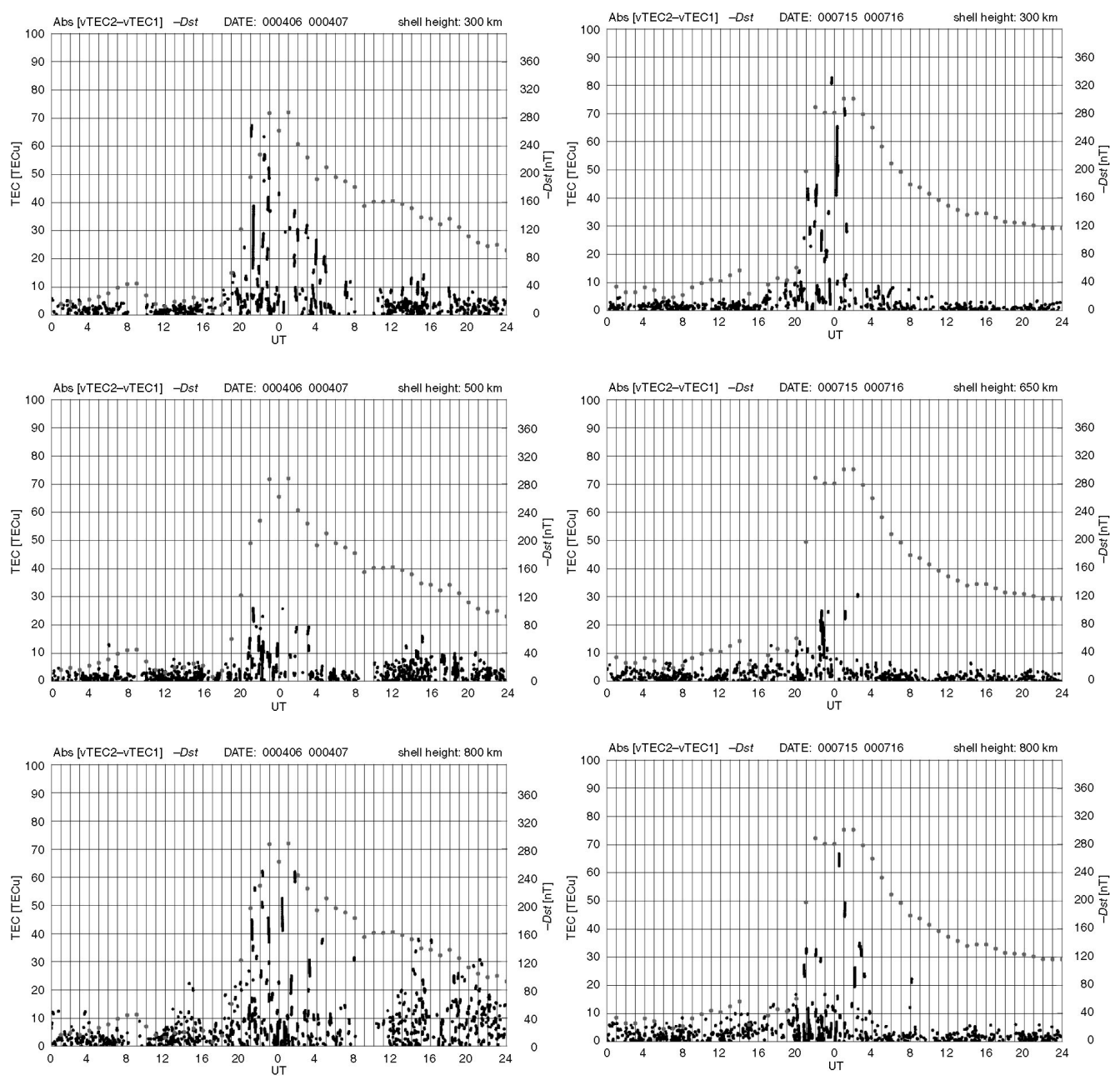

Fig. 18.9. $\triangle \mathrm{TEC}$ quantities and - Dst index values as a function of UT at different shell heights for April 0607 (first column) and for July 15-16, 2000 (second column). 
Due to the scarceness of vTEC data at coinciding pierce points, no sophisticated $\triangle T E C$ minimization method was used to infer the best shell height during the geomagnetic disturbed periods. A simple inspection on $\triangle$ TEC plots as a function of UT for different heights was enough to indicate a suitable shell height able to minimize conversion errors when $D s t$ index reached its minimum values. During April storm this height was at about $500 \mathrm{~km}$, while during July storm conversion errors could be minimized using a shell height of about $650 \mathrm{~km}$.

Figure 18.9 summarizes the analysis done on $\triangle \mathrm{TEC}$ values calculated for different shell heights.

From the same figures it is also possible to estimate the mapping function errors magnitude also during periods that are not highly disturbed. In these cases the ionosphere shell height has an impact not as relevant as in the case of very geomagnetic disturbed periods.

\subsection{IONOSPHERIC TOPSIDE MODELS COMPARED WITH EXPERIMENTAL ELECTRON DENSITY PROFILES}

\subsubsection{NeQuick model}

NeQuick model is an ionospheric electron density model, based on the original DGR «profiler» (Di Giovanni and Radicella, 1990). It is a quick-run model for trans-ionospheric applications that allows to calculate both vertical or slant electron density profile and TEC for any specified path (Hochegger et al., 2000; Radicella and Leitinger, 2001). Above $100 \mathrm{~km}$ and up to the F2-layer peak this model uses a modified DGR profile formulation which includes five semi-Epstein layers with modeled thickness parameters and is based on anchor points defined by $f o E, f o F 1$, foF 2 and $M(3000) F 2$ values. The topside is represented by a semi-Epstein layer with a height dependent thickness parameter empirically determined.

The model has been adopted in the ionospheric specifications for the European Space Agency EGNOS project and more recently by ITU-R Recommendations P531-6 as a suitable method for TEC modeling. The standard NeQuick source code is available at: http://www.itu.int/ITU-R/software/ study-groups/rsg3/databanks/ionosph/.

\subsubsection{IRI model}

The International Reference Ionosphere (IRI) is a well known and widely used empirical model of the ionosphere (Bilitza, 1990, 2001). For given location, date and time, IRI describes the electron concentration, electron temperature, ion temperature and ion composition in the altitude range from about $50 \mathrm{~km}$ to $2000 \mathrm{~km}$ as well as TEC. IRI provides monthly averages in the non-auroral ionosphere for magnetically quiet conditions. It is periodically updated and has evolved over the years.

IRI model can be run on-line at http://nssdc.gsfc.nasa.gov/space/model/models/iri.html/ or the source code can be retrieved via anonymous ftp from the NSSDC (National Space Science Data Center) site: ftp://nssdcftp.gsfc.nasa.gov/models/.

\subsubsection{Experimental data used}

The databases of topside electron density profiles from the ISIS-2 (ftp://nssdcfftp.gsfc.nasa.gov/ spacecraft_data/isis/topside_sounder/), IK-19 and Cosmos-1809 satellites (http://antares.izmiran.rssi.ru/projects/IK19/) were used for model comparisons (Coïsson, 2002). Experimental data with better quality were selected for model comparisons. The geographical distributions of the selected profiles are shown in figs. 18.10 and 18.11 . 
In fig. 18.10 the abbreviations indicate the locations of sites where topside sounding data recorded by the satellite were downloaded. ISIS- 2 satellite was on a circular orbit at $1400 \mathrm{~km}$ height and available soundings were recorded from 1972 to 1983, IK-19 satellite was on an elliptical orbit between $500 \mathrm{~km}$ and $980 \mathrm{~km}$ height, available data were recorded in 1979 and 1980. Cosmos-1809 was on a circular orbit at $980 \mathrm{~km}$ height and data used were recorded during 1987.

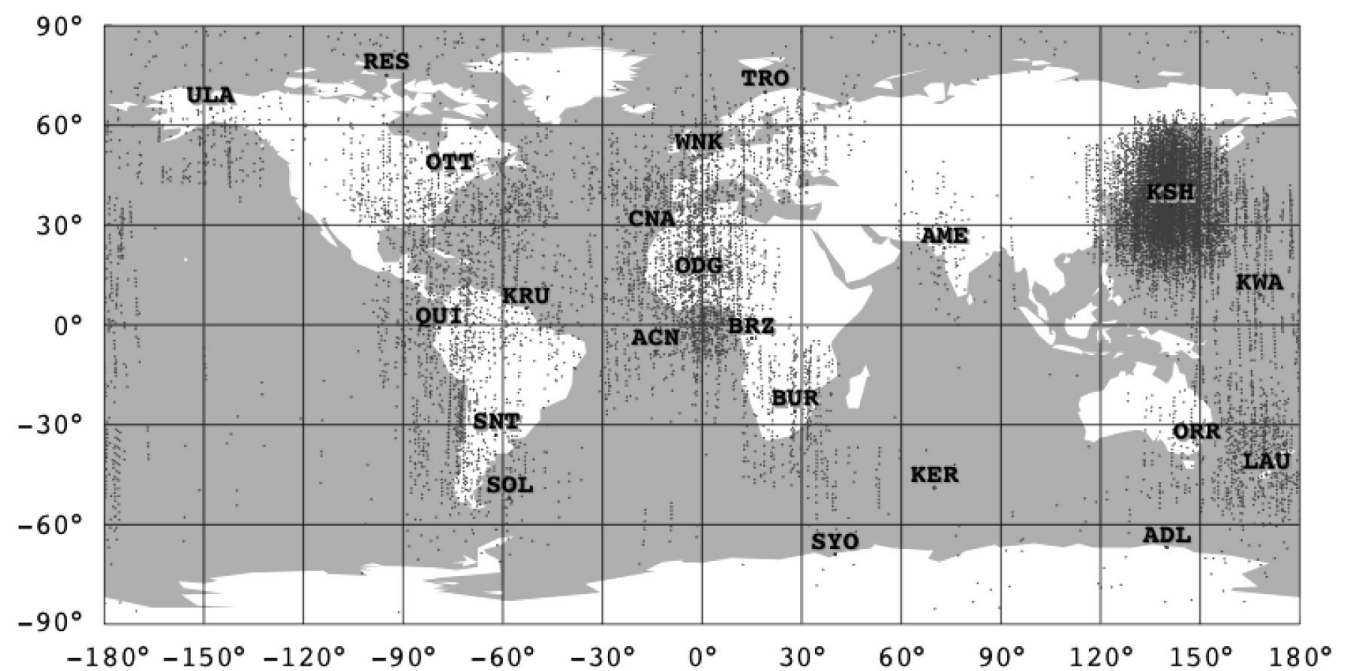

Fig. 18.10. Geographical distribution of the available profiles: ISIS-2 satellite.

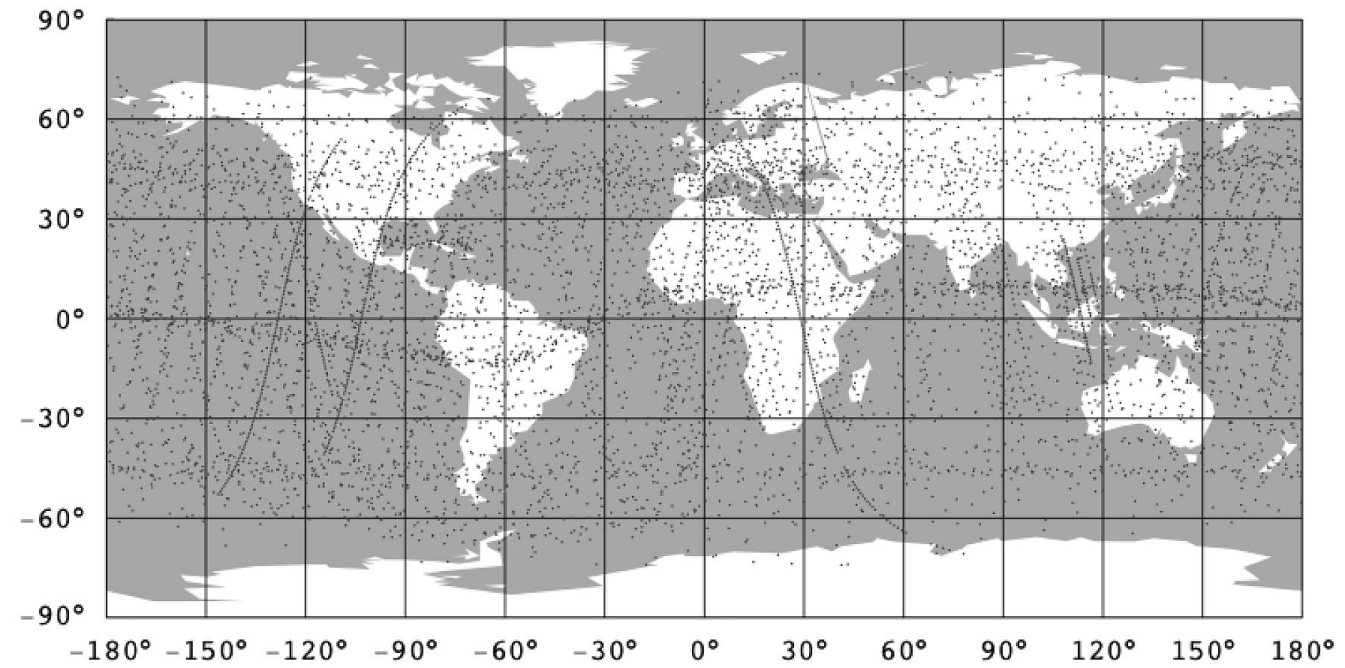

Fig. 18.11. Geographical distribution of the available profiles: IK-19 satellite. 

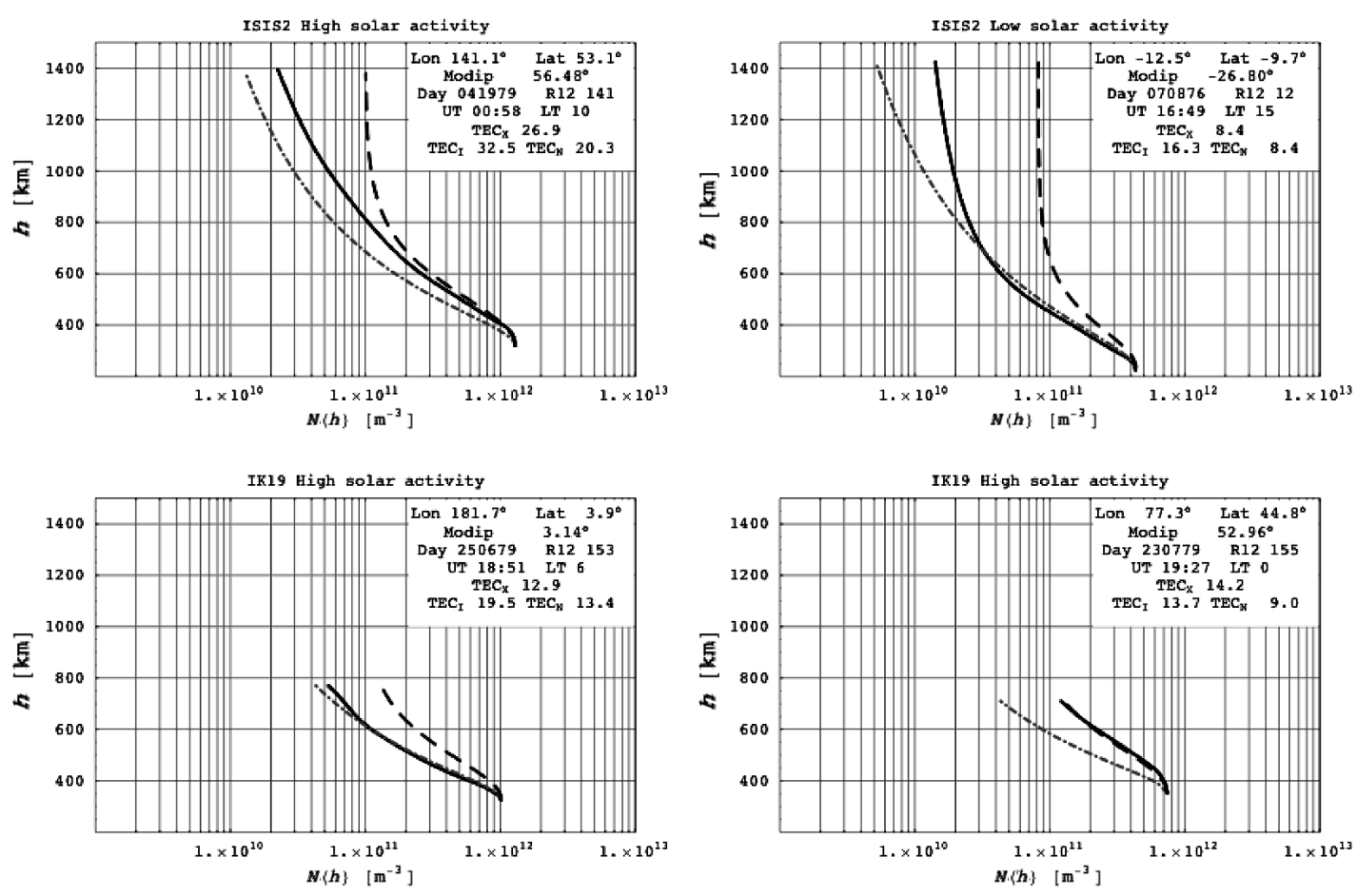

Fig. 18.12. Comparison between experimental profiles from ISIS- 2 and IK-19 data and NeQuick and IRI models. Solid line: experimental; dash-dotted line: NeQuick; dashed line: IRI.

The NeQuick and IRI models were used to compute modeled topside profiles corresponding to the experimental ones; the experimental peak values ( $f o F 2$ and $h m F 2$ ) were provided as input to the models, in order to focus the comparison on the shape of the topside profile. Other inputs provided, which affect the modeled profile shape, are geographic location, universal time and solar activity, expressed by $R_{12}$. Figure 18.12 shows some example of experimental and modeled topside profiles for ISIS-2 and IK-19 satellites.

\subsubsection{Results}

Since there are no universally accepted criteria to compare an experimental profile with a modeled one, two quantities have been compared in this work:

1) Total Electron Content (TEC) from $h m F 2$ up to the satellite height;

2) electron density ratio, Nmodel/Nexp, at a fixed height above the peak.

For statistical purposes, the data have been divided into homogeneous groups of: solar activity level, season of the year, modified dip and local time of the measurement.

Median values and the upper and lower quartiles of the distributions in each sector were computed. Data recorded by different satellites have been kept separated, but the results show a similar behavior. 
In the statistical analysis performed the modified dip (Modip) coordinate has been used. Modip $\mu$ is defined by

$$
\tan \mu=\frac{\psi}{(\cos \phi)^{1 / 2}}
$$

$\psi$ being the true magnetic dip in the ionosphere (usually at $300 \mathrm{~km}$ ) and $\phi$ the geographic latitude (Rawer, 1963). Data have been divided in Modip bands to cover the different regions: equatorial region $\left(-5^{\circ}, 5^{\circ}\right)$, anomaly regions $\left(-35^{\circ},-5^{\circ}\right)$ and $\left(5^{\circ}, 35^{\circ}\right)$, mid-latitudes $\left(-60^{\circ},-35^{\circ}\right)$ and $\left(35^{\circ}, 60^{\circ}\right)$ and high-latitudes $\left(-90^{\circ},-60^{\circ}\right)$ and $\left(60^{\circ}, 90^{\circ}\right)$. Seasons have been named following North-Hemisphere convention: Winter from November to February; Equinox for March, April, September and October; Summer from May to August.

\subsubsection{TEC comparisons}

The differences between each experimental and modeled TEC from $h m F 2$ up to the satellite height have been calculated and the statistical analysis was performed as indicated in the previous section. The most relevant results are described below.

NeQuick model - It shows different behavior on different seasons (fig. 18.13). During winter months it overestimates and underestimates the TEC anti-symmetrically with respect to the magnet-
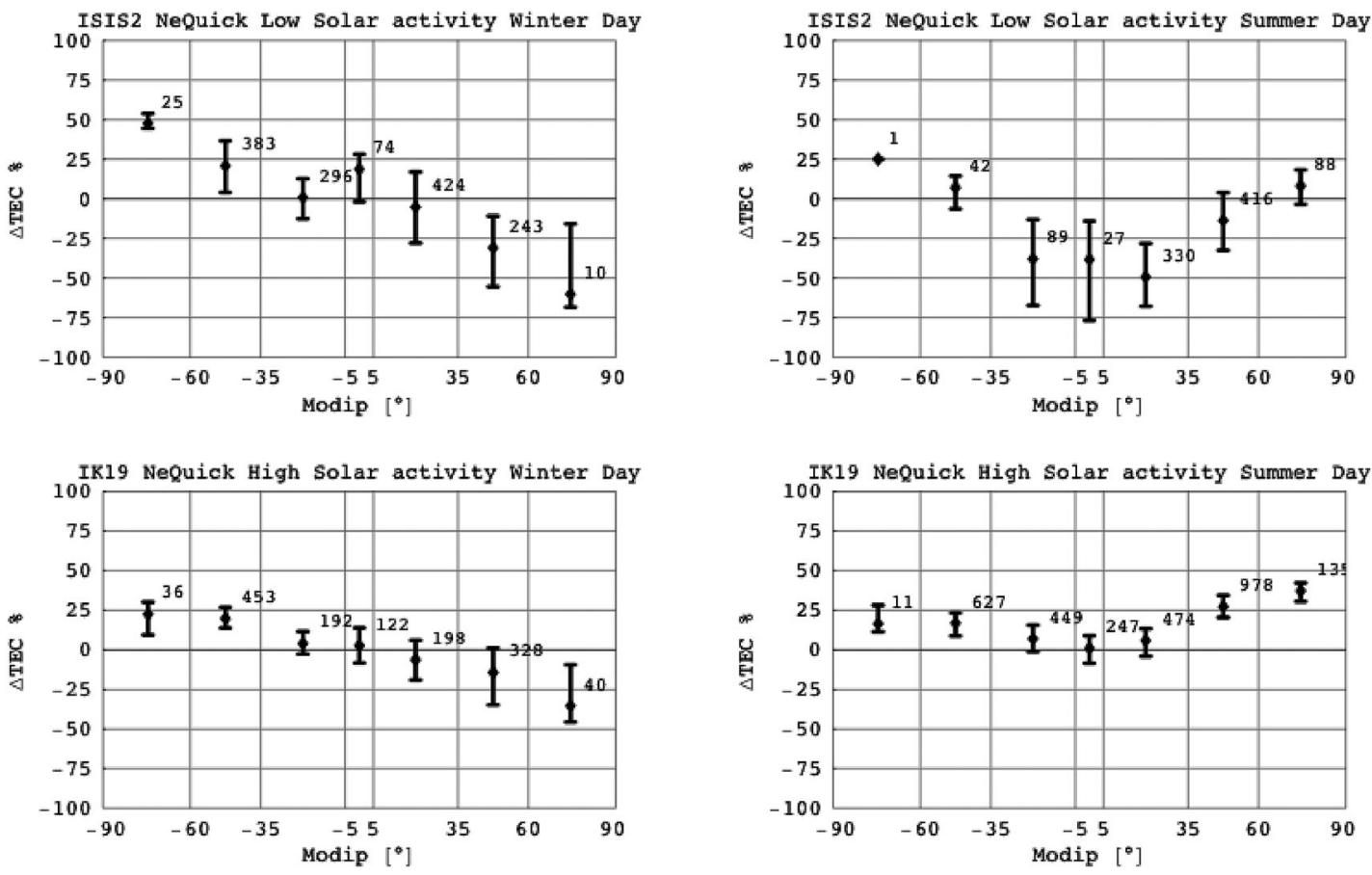

Fig. 18.13. Percent difference between experimental topside TEC and NeQuick topside TEC. Numbers indicate the amount of data in each selection. 

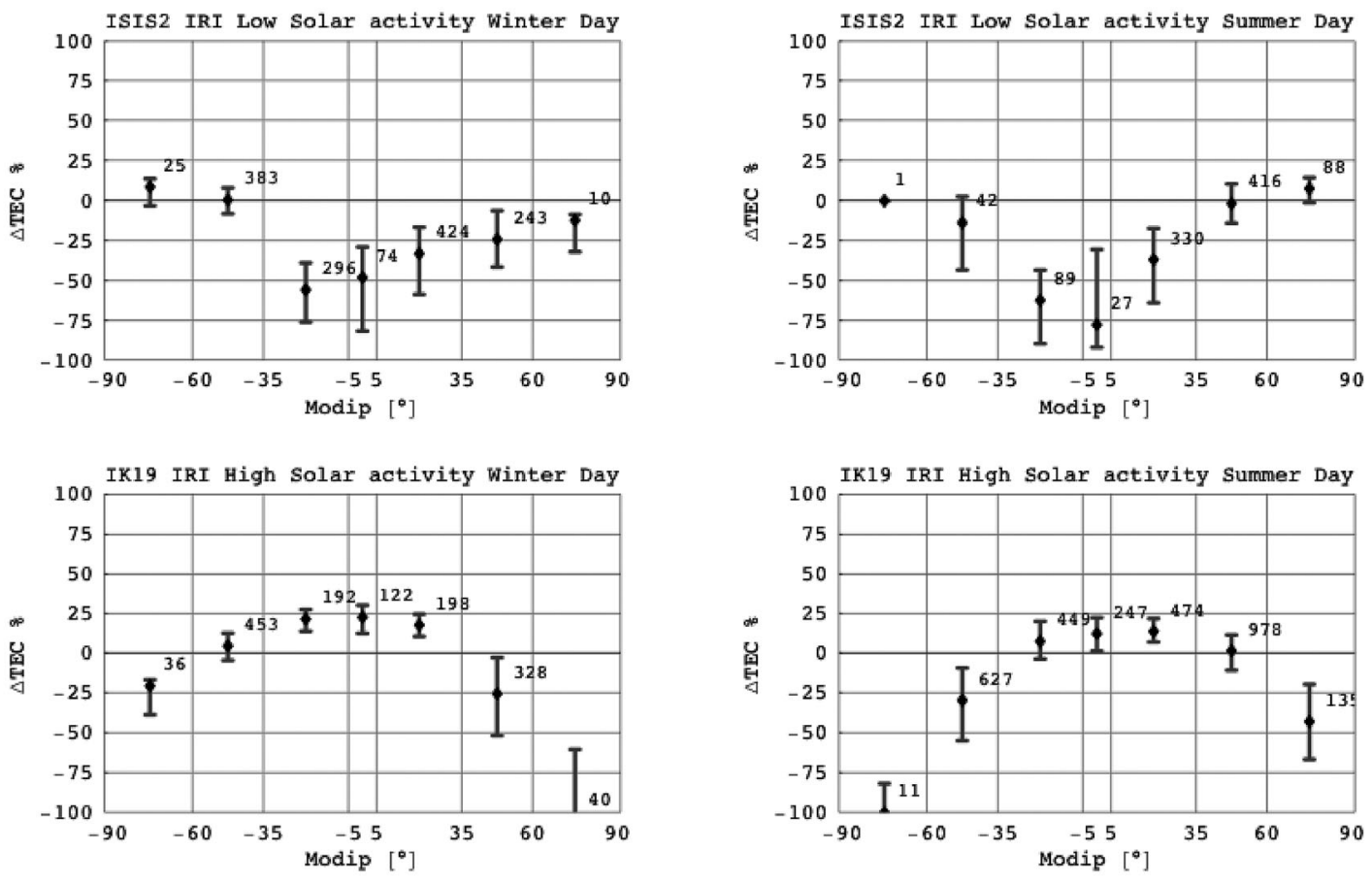

Fig. 18.14. Percent difference between experimental topside TEC and IRI topside TEC. Numbers indicate the amount of data in each selection.

ic equator. During summer months it shows a symmetric behavior, with overestimation at low latitudes and better agreement at medium and high latitudes.

IRI model - It tends to overestimate the topside TEC, showing a behavior dependent on solar activity (fig. 18.14). While during low solar activity there is a greater overestimation at low latitudes and a good agreement at medium latitudes, for high solar activity IRI underestimates TEC in the equatorial region but strongly overestimates it at high latitudes.

\subsubsection{Electron density comparisons}

The experimental and modeled electron densities $1000 \mathrm{~km}$ above $h m F 2$ were compared. This height was reached only in the ISIS-2 profiles, but it was chosen to have an idea about the way models behave on the upper part of the profile. IRI model is in fact used up to $2000 \mathrm{~km}$ and NeQuick up to $20000 \mathrm{~km}$. Thus it is important to understand how much they are reliable in the upper part of the profile.

NeQuick model - It shows a seasonal behavior similar to the one observed for topside TEC (fig. 18.15), the electron density values being always between $25 \%$ and $200 \%$ of the experimental ones.

IRI model - It always overestimates the electron density (fig. 18.16), showing different Modip behavior depending on solar activity level. The values are greater than $200 \%$ and up to $1000 \%$ of the experimental ones. In addition, at high latitudes for high solar activity, cases have been found in which the IRI electron density is not decreasing with height. 

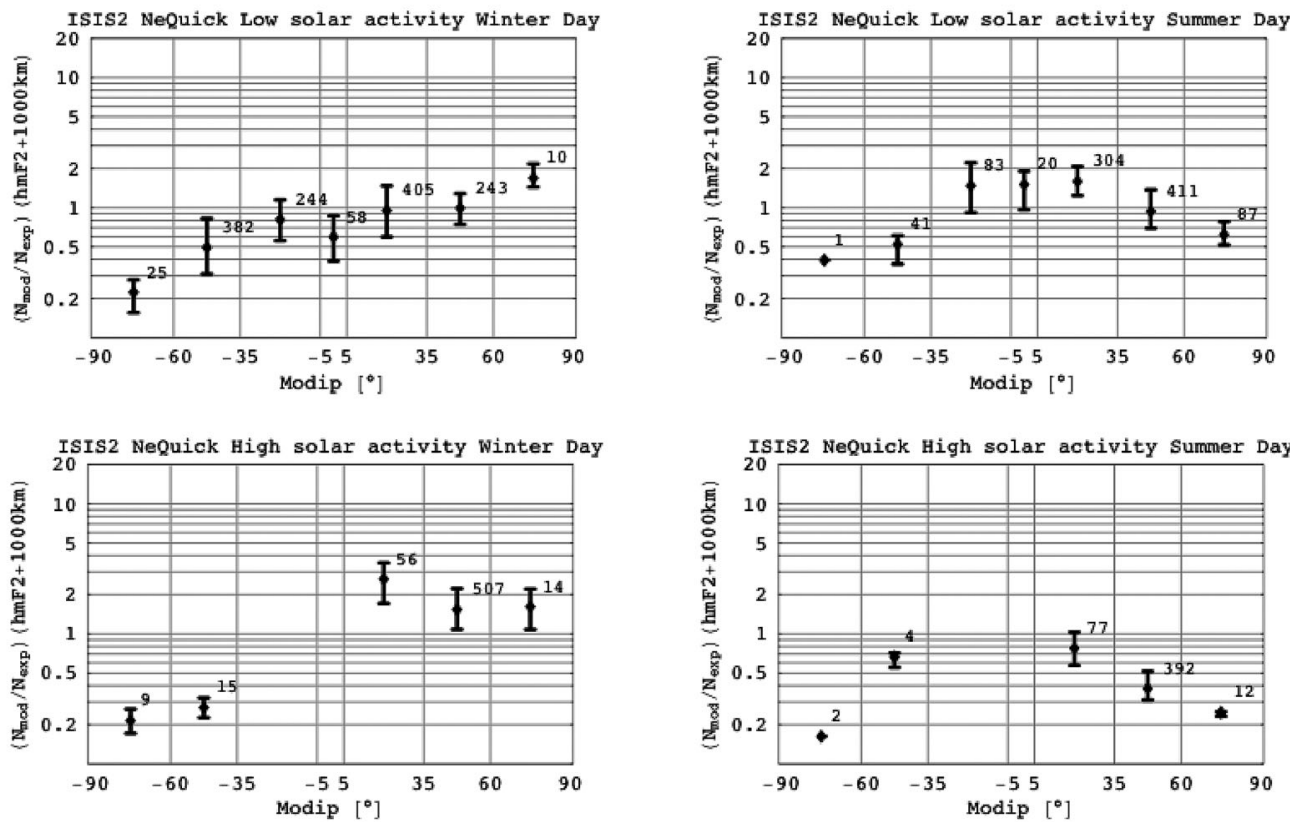

Fig. 18.15. Ratio between NeQuick and experimental electron density $1000 \mathrm{~km}$ above $h m F 2$. Numbers indicate the amount of data in each selection.
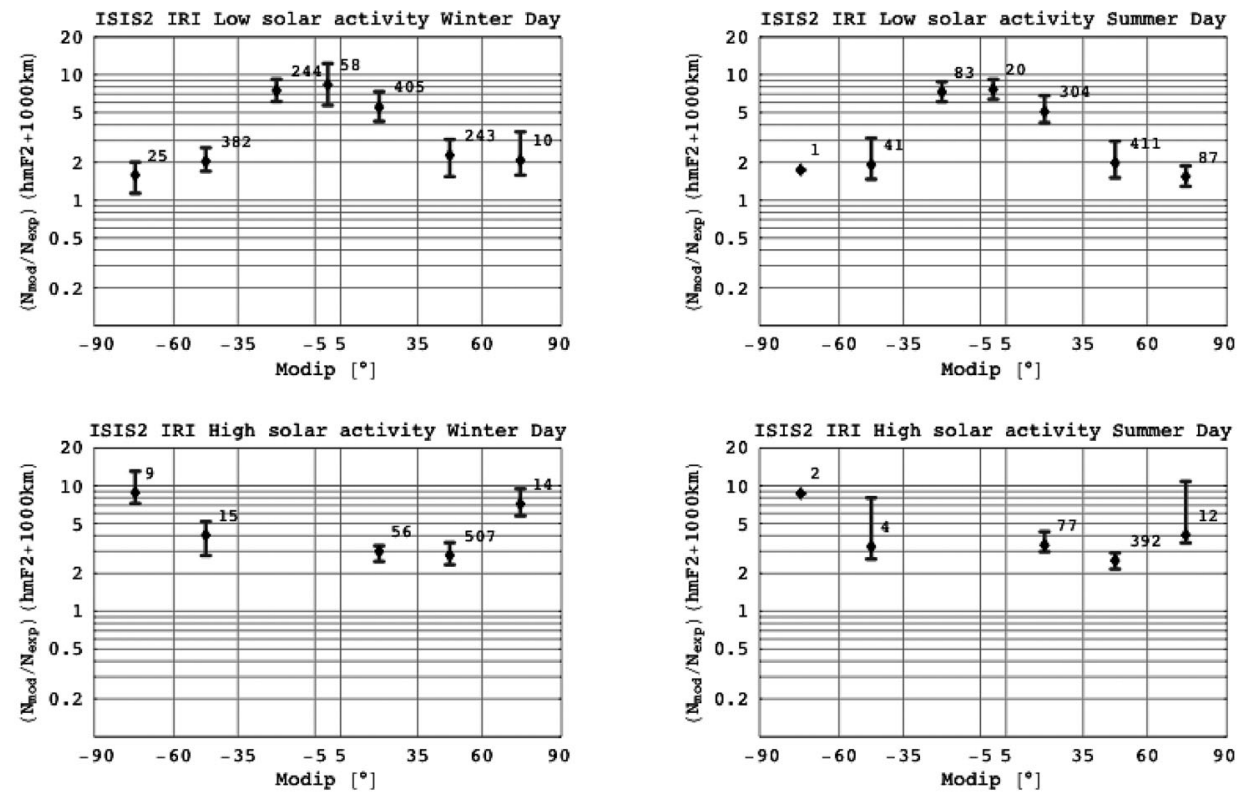

Fig. 18.16. Ratio between IRI and experimental electron density $1000 \mathrm{~km}$ above $h m F 2$. Numbers indicate the amount of data in each selection. 


\subsection{Total ELECTRON CONTENT ALONG SATELLITE-TO-SATELLITE PATHS} (Bailey and Kersley, 2003)

\subsubsection{Model simulations}

The Sheffield University Plasmasphere Ionosphere Model (SUPIM) is a proven physical model of processes in the atmosphere within the plasmapause. It enables estimates to be made of electron densities in the ionosphere/plasmasphere system at low and mid latitudes on a global scale. It has already been used successfully in propagation studies to validate GPS measurements of TEC using the SCORE process and to estimate the contribution of the protonosphere to the GPS-TEC (Lunt et al., 1999a-d). SUPIM has now been used in this study to estimate TEC on satellite-tosatellite paths.

The investigations have concentrated on trying to assess the magnitudes of the TECs likely to be encountered on the very long satellite-to-satellite paths and to identify the circumstances that give rise to the largest TECs. In consequence, the studies have been concerned in the main with geometry close to the equatorial plane, exploring the TEC values along the long tangential paths through the equatorial ionosphere near to the eclipse of the GPS satellite when viewed from the geostationary orbit. Since potential interest concerns the effects of extreme conditions, the model has been run for a solar flux input of 250 units, appropriate to a large solar maximum, with the $\boldsymbol{E} \times \boldsymbol{B}$ drift magnitude chosen to give rise to a well-developed equatorial anomaly.

\subsubsection{Results}

It should be noted that along ray paths well away from eclipse situations the TEC estimates are generally less that $20 \mathrm{TECU}$ so that the positioning errors are likely to be only a few metres. However, circumstances are very different when the paths follow grazing trajectories close to the layer peak of the equatorial ionosphere. It was found that the TEC values were very sensitive to the detailed geometry of the ray path through the ionosphere. In consequence, rather than replicating the precise orbits for the GPS constellation, it was decided to investigate the TECs encountered when a satellite at GPS altitude was moved close to eclipse, first in the equatorial plane and secondly in latitude.

The intention was to acquire relevant information on approximate magnitudes of the TECs likely to be encountered, rather than precise details corresponding to particular geometrical situations. A large numbers of simulations have been run to amass data for a wide range of circumstances. However, the presentation here is confined to a few representative examples that are illustrative of the results obtained.

Figure 18.17 is typical of the TECs found when both satellites are in the equatorial plane, with the ray-path geometry close to eclipse. In the example, the geostationary satellite is located at $0^{\circ}$ longitude at various universal times, with the second satellite at GPS altitude and a succession of longitudes, ranging from $153^{\circ} \mathrm{E}$ until the ray path eclipses below the Earth horizon when the satellite is about $156.5^{\circ} \mathrm{E}$ longitude. It can be seen that between 6 UT and 12 UT there is a band of ray-path geometries for which the TEC exceeds 1000 TEC.

The diurnal change in the maximum TEC along ray paths close to eclipse in the equatorial plane is illustrated in fig. 18.18. Here the geostationary satellite is again at $0^{\circ} \mathrm{E}$ with the second satellite now to the west near $205^{\circ} \mathrm{E}$ longitude. It can be seen that the maximum TEC varies with time by a factor of about 4, from some 300 TECU before 12 UT to more than 1200 TECU later in the day.

Even larger TEC magnitudes were found for ray-path geometries out of the equatorial plane.

An illustrative example is shown in fig. 18.19 where the TEC values come close to 2000 TECU. The particular situation corresponds to 6 UT with the geostationary satellite at $60^{\circ} \mathrm{E}$ longitude and second satellite at $215.71^{\circ} \mathrm{E}$ longitude, but some $4^{\circ}$ south of the equatorial plane in latitude. It is interesting to note that the largest TEC values do not correspond to ray paths 

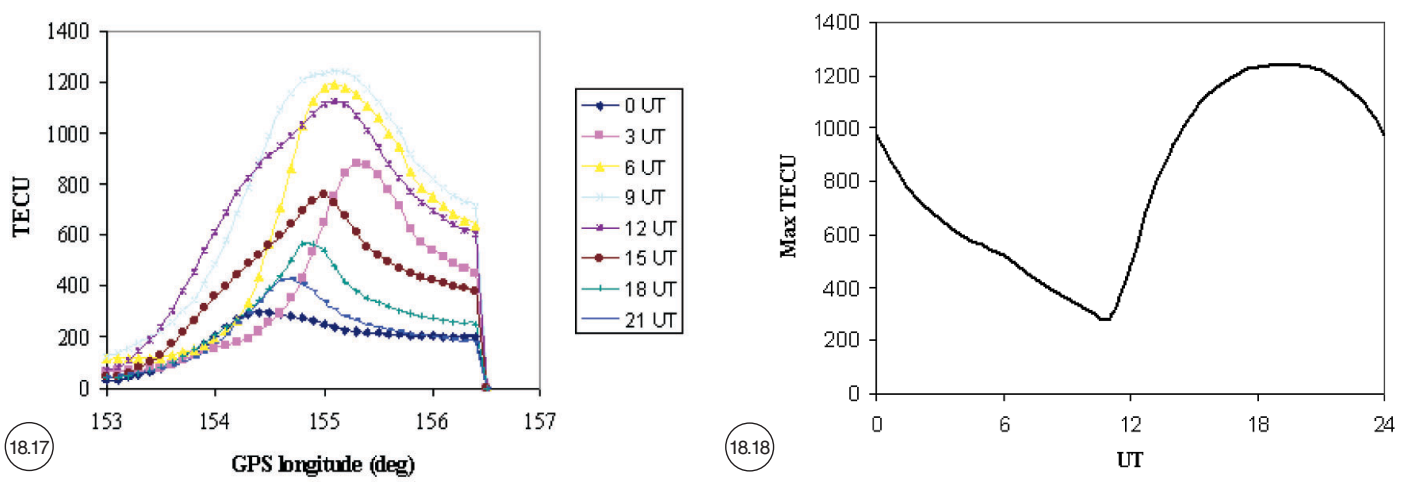

Fig. 18.17. TEC from GPS satellite to a Geostationary satellite located at $0^{\circ}$ longitude with ray-path geometry near eclipse. Both satellite in the equatorial plane.

Fig. 18.18. Maximum TEC versus UT for a path from GPS satellite at a longitude of $205^{\circ} \mathrm{E}$ to a Geostationary satellite at a longitude of $0^{\circ}$.

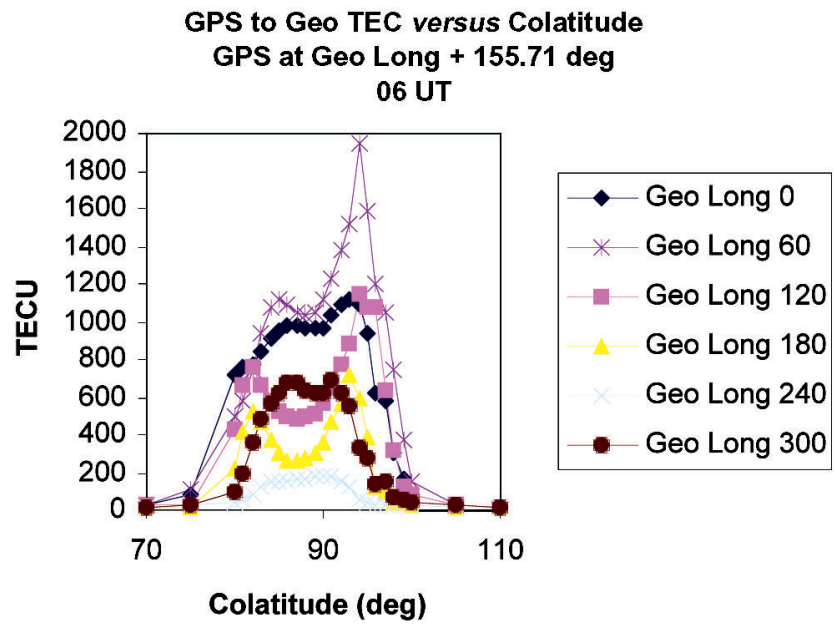

Fig. 18.19. TEC versus colatitude for ray-path from GPS satellite to Geostationary satellite.

through the crests of the equatorial anomaly. The effects of ionisation distribution, Earth curvature, and ray-path geometry combine to give high TEC values for a band of GPS satellite latitudes spanning some $20^{\circ}$ about the equator.

Figure 18.19 also demonstrates that the TEC values for essentially similar ray-path geometries but in different longitude sectors can vary by almost two orders of magnitude. 


\subsection{Conclusions}

1) Thin shell approximation errors behavior with respect to satellite elevation angle and azimuth is determined by spatial electron density gradients.

The results obtained suggest a way to «build-up» a correcting error function, that applied to Vertical TEC, could allow to «bound» the error on Slant TEC after «back conversion».

Appropriate model simulations could indicate the influence of thin shell curvature, latitudinal and longitudinal gradients on conversion error as a function of location and satellite elevation and azimuth. Checks of the results obtained with the simulations can be done using experimental GPS derived sTEC.

Supertruth data allowed to visualize some features of the ionosphere during geomagnetic storms. The coinciding pierce point technique has shown that a strong correlation between $D s t$ index variation and mapping function errors magnitude exists. Since mapping function errors reflect the presence of strong electron density and TEC gradients, the coinciding pierce point technique indicated that in some cases it is possible to detect some ionospheric storm effects in near-real-time. In addition, it was shown that, in some cases, also high sTEC rate of change values are related to lower values of Dst index indicating the presence of ionospheric structures of different scale that are responsible for strong electron density and TEC gradients.

Nevertheless, due to the scarceness of data coverage, it must be noted that the absence of mapping function errors or relevant STEC rate of change, does not indicate the presence of quiet ionosphere conditions.

2) A comparison between 20000 topside electron density profiles from satellite measurements and computed by NeQuick and IRI models have been performed. The attention was focused on TEC and electron density at $1000 \mathrm{~km}$ above the $F 2$ peak. The wide set of different experimental conditions has allowed pointing out many of the characteristics of each model.

NeQuick topside is a modified Epstein layer. An empirical relation, related to the month of the year, governs its thickness parameter. From the present study it appears that the model performance is strongly affected by this parameter, indicating the need for an improvement of its formulation.

IRI is based on Booker's approach to model the topside by dividing it into two parts with constant height gradients. The gradients depend on latitude, solar activity and $f o F 2$. In the present study it appears that this formulation leads to overestimate the electron density in the upper part of the profiles, and consequently to overestimate TEC.

3) The model simulation study for GPS-to-geostationary satellite ray paths has shown that very large TEC values may be encountered. It must be noted that for some extreme situations where the trajectory traverses the equatorial ionosphere at grazing incidence the TEC estimates could give rise to positioning errors in excess of $0.5 \mathrm{~km}$. It is clear from the study that in any use of GPS signals for the station-keeping of geostationary satellites it would be necessary to exclude any dependence on signals where the ray-path geometry is close to eclipse, particularly close to the equatorial plane. However, for most ray paths between the satellites, through the plasmasphere but far removed from eclipse by the Earth horizon, the TEC magnitudes are small enough for metre accuracy to be achieved in the positioning estimates.

\section{REFERENCES}

BAILEY, G.J. and L. KERSLEY (2003): Extreme total electron contents along satellite-to-satellite paths, in Proceedings of the 3rd COST 271 Workshop, 23-27 September 2003, Spetses, Greece.

BILITZA, D. (1990): International Reference Ionosphere 1990, in NSSDC 90-22, Greenbelt, Maryland. BilitZA, D. (2001): International Reference Ionosphere 2000, Radio Sci., 36 (2), 261-275.

Bilitza, D., B.W. Reinisch, R. Benson, J. Grebowsky, N. Papitashvili, X. Huang, W. Schar and 
K. HILLS (2003): Online database of satellite sounder and in situ measurements covering two solar cycles, Adv. Space Res., 31 (3), 769-774.

Breed, A.M., A. L. Goodwin, A. M. Vandenberg, E. A. Essex, K. J. W. Lynn and J.W. Sylby (1997): Ionospheric total electron content and slab thickness determined in Australia, Radio Sci., 32 (4), 1635-1643.

CoÏsson, P. (2002): Uso di dati sperimentali per la convalida di modelli ionosferici applicati al disegno di servizi e sistemi satellitari, Thesis (Università di Trieste).

Davies, K. and G.K. HARTMAnN (1997): Studying the ionosphere with the Global Positioning System, Radio Sci., 32 (4), 1695-1703.

Di Giovanni, G. and S.M. Radicella (1990): An analytical model of the electron density profile in the ionosphere, Adv. Space Res., 10 (11), 27-30.

Hochegger, G., B. NAvA, S.M. Radicella and R. Leitinger (2000): A family of ionospheric models for different uses, Phys. Chem. Earth, 25 (4), 307-310.

Leitinger, R., P. Spalla and L. Ciraolo (1999): Latitude dependent mean ionospheric height a new approach to the TEC evaluation from NNSS data, Acta Geod. Geophys. Hung., 33 (1), 61-73.

LunT, N., L. Kersley and G. J. BAILEY (1999a): The influence of the protonosphere on GPS observations, Model simulations, Radio Sci., 34, 725-732.

Lunt, N., L. Kersley, G.J. Bishop, A.J. Mazzella and G.J. Bailey (1999b): The effect of the protonosphere on the estimation of GPS-TEC: Validation using the SUPIM model, Radio Sci., 34, 1261-1271.

LunT, N. , L. KeRsLey, G.J. Bishop and A.J. MAZZella (1999c): The contribution of the protonosphere to GPS total electron content: Experimental measurements, Radio Sci., 34, 1273-1280.

Lunt, N. , L. Kersley, G. J. Bishop, A.J. MAzzella JR and G.J. BAiley (1999d): The protonospheric contribution to GPS-TEC: Two-station measurements, Radio Sci., 34, 1281-1285.

NAvA, B. (2000): Modello di densità elettronica della ionosfera applicato alla navigazione satellitare, Thesis (Università di Trieste).

NAVA, B. and S.M. RADICELla (2003a): Ionosphere response to geomagnetic storm as seen by GPS derived total electron content data, in Proceedings of 2003 International Symposium on GPS/GNSS, Tokyo, Japan, 325-329.

NAVA, B. and S.M. RAdicElla (2003b): Use of 'Supertruth' data to analyze ionosphere behavior during geomagnetic disturbed periods, in Proceedings of Atmospheric Remote Sensing Using Satellite Navigation Systems, Matera, Italy.

Radicella, S.M. and R. Leitinger (2001): The evolution of the DGR approach to model electron density profiles, Adv. Space Res., 27 (1), 35-40.

RAWER, K. (1963): Propagation of decameter waves (HF-band), in Meteorological and Astronomical Influences on Radio Wave Propagation, edited by B. LANDMARK (New York Academic Press). 